\title{
Literature Review : Pengalaman Ayah yang Memiliki Bayi Prematur di NICU
}

\author{
Minarni
}

\section{Kelahiran Prematur}

Diperkirakan 15 juta bayi lahir terlalu dini setiap tahun. Hal ini menunjukkan lebih dari 1 dari 10 bayi mengalami kelahiran dini. Hampir 1 juta anak meninggal setiap tahun akibat komplikasi dari kelahiran prematur. Tingkat kelahiran prematur meningkat hampir pada semua negara. Indonesia merupakan peringkat 5 dari 10 negara dengan kelahiran prematur dan masuk peringkat 9 dengan 15,5 kelahiran prematur per 100 kelahiran hidup dari 10 negara (Blencowe et al, 2014).

Kelahiran prematur didefinisikan sebagai persalinan yang terjadi pada kurang dari 37 minggu atau 259 hari kehamilan. Kelahiran prematur merupakan penentu utama kematian dan kesakitan neonatal yang memiliki konsekuensi jangka panjang yang merugikan bagi kesehatan anak. Kelahiran prematur adalah salah satu masalah yang paling signifikan diperinatologi. Neonatal yang lahir prematur memiliki resiko lebih tinggi mengalami cerebral palsy, defisit sensorik, ketidakmampuan belajar dan penyakit pernapasan. Kesakitan yang berhubungan dengan kelahiran prematur sering meluas kekehidupan selanjutnya, sehingga biaya fisik, psikologis dan ekonomi menjadi sangat besar (Beck et al, 2009).

Senada dengan Beck et al (2009), Blencowe et al (2014) juga mengungkapkan bahwa neonatal prematur yang hidup biasanya mengalami kecacatan, termasuk ketidakmampuan belajar, masalah visual dan pendengaran. Secara global, prematuritas adalah penyebab utama kematian pada anak-anak di bawah usia 5 tahun.

2. Lingkungan Perawatan Neonatal intensive care unit (NICU)

Neonatal prematur mengalami masa transisi ke kehidupan ekstra-uterin dengan sistem organ yang belum matang dan belum berkembang. Hal ini membuat neonatal prematur membutuhkan perawatan di ruangan intensif. Neonatal intensive care unit (NICU) merupakan unit perawatan khusus di rumah sakit untuk perawatan neonatal sakit dan prematur. Dalam unit perawatan ini, lingkungan fisik dan psikologis merupakan faktor penting bagi perkembangan neonatal dan lamanya waktu perawatan (Hunt, 2011).

Lingkungan fisik NICU menunjukkan adanya batasan bagi orangtua seperti inkubator yang dianggap mengisolasi bayi, suara-suara dari peralatan yang menakutkan dan bayi-bayi yang terlihat lemah yang membutuhkan peralatan teknologi tinggi (Kenner \& McGrath, 2004). Lingkungan fisik berupa pencahayaan, kebisingan, peralatan dan berbagai prosedur tindakan yang dilakukan (Hunt, 2011). Lingkungan psikologis juga berpengaruh bagi perawatan neonatal yang meliputi dukungan komunikasi dari pemberi pelayanan, stress orangtua dan perkembangan bayi (Hunt, 2011).

3. Pengalaman Orangtua di NICU

Pengalaman memiliki bayi yang dirawat di NICU bagi orangtua dan pengasuh bayi merupakan pengalaman yang luar biasa, traumatis dan berpengaruh pada perubahan kehidupan. Pengalaman di NICU dapat menyebabkan orangtua mengalami ketakutan dan kerentanan yang tidak stabil. Orangtua mengalami sedih mendalam atas kemampuan bayinya untuk bertahan. Kepercayaan orangtua menjadi terganggu, karena mereka berperilaku dan berpikir dengan cara-cara yang tidak pernah dirasakan atau terpikirkan sebelumnya (Vandenberg, Perez, \& Newstetter, 2008).

Lingkungan NICU yang asing dengan berbagai peralatan berteknologi tinggi, banyaknya staf yang merawat bayi dan ketidaktahuan apa yang harus dilakukan menimbulkan perasaan 
ketidakberdayaan dan dapat menyebabkan stres pada orangtua bayi yang dirawat (American Academy of Pediatrics [AAP], 2010). Penyebab stres yang lain diantaranya yaitu pemisahan orangtua dengan bayinya, konflik dengan pasangan dan ketidakjelasan dalam peran (Hall \& Brinchmann, 2009).

Sumber stres yang dialami orangtua di NICU antara lain karena faktor pribadi/keluarga, kondisi situasional dan lingkungan fisik serta psikososial NICU. Yang termasuk faktor pribadi misalnya kepribadian, mekanisme koping dan pengalaman sebelumnya. Kondisi situasional termasuk penyakit dan ketidakpastian hasil dari perawatan bayi, sedangkan faktor lingkungan mencakup penampilan bayi dan komunikasi/hubungan dengan staf NICU (Heermann et al, 2005).

Orangtua menunjukkan berbagai reaksi dan emosi pada saat awal bayinya dirawat di NICU. Reaksi ini tergantung harapan orangtua terhadap kelahiran bayi, kondisi bayi, kondisi orangtua sendiri dan pengalaman sebelumnya. Reaksi orangtua yang timbul diantaranya marah, kehilangan dan ketidakberdayaan. Kemarahan juga merupakan reaksi umum pada awal pengalaman orangtua di NICU. Pada umumnya orangtua akan mengekspresikan kemarahannya dengan cara yang berbeda seperti marah secara terbuka, menuntut, dan menyalahkan orang lain (AAP, 2010).

Melihat bayi yang prematur atau sakit, orangtua mengalami perasaan kehilangan atas apa yang diharapkan untuk pertama kalinya. Orangtua juga mungkin akan merasa kehilangan peran, seperti selama kehamilan ibu bayi membayangkan dirinya akan menjadi orangtua yang bisa merawat dan bermain dengan bayinya. Sementara, ketika bayi yang dilahirkannya mengalami sakit atau prematur, orangtua harus menghabiskan waktu dengan bayinya di lingkungan yang asing, menyentuh bayi hanya melalui jendela inkubator dan menunggu staf NICU untuk memberitahu kapan saat yang tepat untuk memegang atau memberi makan bayi (AAP, 2010). Arnold et al. (2013) melaporkan penelitiannya tentang momen pertama orangtua dengan bayi prematurnya. Penelitian ini menggunakan studi kualitatif dengan wawancara semi terstruktur pada 32 Ibu dan 7 Ayah yang memiliki bayi prematur $<32$ minggu. Hasil dari penelitian ini berupa lima tema yang teridentifikasi yaitu (1) Orang tua mengalami mengalami emosi yang naik turun; (2) Emosi yang berlainan saat orangtua melihat dan menyentuh bayinya untuk pertama kalinya; (3) Menggambarkan pandangan pertama orangtua dan sentuhan bagi bayinya dan emosi yang naik turun; (4) Kesan orangtua adalah luar biasa, terutama untuk orangtua yang belum pernah mengunjungi NICU sebelumnya atau yang pertama melihat bayi mereka di NICU; (5) Menangkap pengalaman unik ayah, khususnya bahwa banyak yang merasa diabaikan dan bingung tentang peran mereka.

Heidari, Hasanpour dan Fooladi (2013) melaporkan penelitian kualitatif yang dilakukan pada 21 partisipan (6 ayah, 7 ibu, 5 perawat dan 3 dokter) tentang reaksi stres orangtua dengan bayi yang dirawat di NICU. Partisipan orangtua dalam penelitiannya mendefinisikan stres sebagai pengalaman yang signifikan yang memicu rasa was-was, kegelisahan, ketegangan emosional atau tekanan kecemasan. Kebanyakan orangtua setuju bahwa stres dikombinasikan dengan kegelisahan, ketakutan dan ketidakseimbangan emosional.

Tandberg, Sandtro, Vardal dan Ronnestad (2013) melakukan penelitian kuantitatif dengan desain survei deskriptif komparatif pada 82 orangtua yang memiliki bayi prematur. Penelitian ini bertujuan untuk mengevaluasi stres orangtua (menggunakan Parental Stressor Scale: Neonatal Intensive Care Unit/PSS : NICU) dan persepsi orangtua terhadap dukungan keperawatan (menggunakan Nursing Parent Support Tool/NPST). Hasil penelitian menunjukkan bahwa umumnya ibu dan ayah memiliki pengalaman tingkat stres yang tinggi terhadap penampilan bayi mereka yang dirawat di NICU. Beberapa pengalaman stres mencakup peran orangtua dan perubahan dari peran itu.

Penelitian lain dilakukan oleh Busse, Stromgren, Thorngate dan Thomas (2013) pada 30 orangtua tentang respon stress orangtua yang bayinya dirawat di NICU. Penelitian ini juga 
menggunakan instrumen Parental Stressor Scale: Neonatal Intensive Care Unit/PSS : NICU (menilai tanda dan suara di NICU dan penampilan bayi) terhadap respon orangtua yang berupa kecemasan, depresi, kelelahan dan gangguan tidur (menggunakan Patient Reported Outcomes Measurement Information System/PROMIS instruments). Hasilnya, pengalaman stres orangtua berhubungan dengan kekhawatiran fisik dan emosional seperti kecemasan, depresi, kelelahan dan gangguan tidur.

Heidari et al. (2013) menjelaskan bahwa reaksi stres orangtua masuk dalam kategori keadaan psikologis pikiran yang mengarah ke reaksi emosional dan perilaku. Dalam penelitiannya setelah bayi diserahkan perawatan ke NICU, beberapa partisipan rentan berperilaku tidak rasional dan menunjukkan reaksi emosional yang parah dengan menangis, gelisah, ketidaknyamanan fisik dan ketidakstabilan mental. Seorang ibu (24 tahun) mengatakan : "...Aku tidak dapat beristirahat di tempat tidur, bolak-balik untuk minum air; Aku harus memeriksa pintu NICU setiap 5-10 menit".

Reaksi emosional yang ditunjukkan berupa adanya perasaan takut dan bersalah. Ketakutan adalah reaksi normal. Pada umumnya orangtua memiliki sedikit pengalaman sebelumnya terkait bayi yang baru lahir dengan kondisi sakit ; banyak yang tidak nyaman dengan lingkungan NICU dan khawatir tentang bayi mereka. Orangtua juga takut bayinya kemungkinan mengalami penyakit serius, cacat bahkan kematian. Seorang ibu terkadang takut pasangannya akan menyalahkan mereka atas kelahiran yang sulit dan takut kehilangan hubungan. Seringkali ibu bayi merasa bahwa ibunya atau ibu mertua menilai dia yang bertanggung jawab untuk masalah bayi. Ketakutan dan was-was biasanya menurun dari waktu ke waktu, tetapi sebagian besar orang tua merasa khawatir pada awal bayi mereka dirawat di NICU (AAP, 2010).

Ketakutan adalah reaksi emosional karena memburuknya kondisi kesehatan bayi. Seorang ibu 23 tahun mengatakan : "...Saya takut melihat dia, takut untuk melihat kondisi kesehatan dan bagaimana ia terlihat sekarang...". Penekanan perasaan lebih umum pada ayah bayi. Seorang ayah 28 tahun mengatakan : "Saya tidak bisa mengatakan banyak tentang perasaan saya" (Heidari et al., 2013).

Kebanyakan orangtua mengekspresikan perasaan bersalah setelah bayi yang dilahirkan mengalami sakit atau prematur. Perasaan bersalah ini terutama ditunjukkan oleh ibu yang merasa menjadi penyebab bayinya sakit atau prematur akibat tidak menjaga kehamilannya dengan baik (AAP, 2010).

Dalam kondisi bayi yang dirawat di NICU, sebagian besar orangtua telah kehilangan nafsu makan dan tidak dapat tidur. Perilaku orangtua berbeda dengan peningkatan gelisah dan kecemasan dan memeriksa status kesehatan bayi mereka terus menerus. Seorang ibu 24 tahun itu mengatakan : "...Aku hanya menangis di hari pertama dan kedua, aku bahkan tidak bisa minum segelas air. Aku mengunjungi dia dan mulai menangis ketika aku melihat semua halhal yang melekat pada dirinya. " Seorang perawat 26 tahun dengan dua tahun pengalaman mengatakan : "...Selain gelisah dan kecemasan, kebanyakan orangtua mengeluh tidak bisa tidur di malam hari, karena hati orangtua ada di NICU" (Heidari et al., 2013).

4. Pengalaman Ayah Bayi di NICU

Steedman (2007) melaporkan bahwa pengalaman stres ibu lebih tinggi dibandingkan ayah terkait untuk keseluruhan pengalaman NICU dan setiap aspek yang ada seperti pemandangan dan suara, penampilan dan perilaku bayi, perubahan hubungan orangtua-bayi dan komunikasi dengan staf. Namun, ditemukan aspek yang membuat ayah bayi paling stres yaitu pemandangan dan suara-suara di lingkungan perawatan NICU.

Johnson (2008) melaporkan bahwa ayah jauh lebih sulit untuk terlibat dalam perawatan bayinya di NICU. Pohlman (2009) mewawancarai 8 orang ayah (berusia 22-40 tahun) di NICU yang memiliki bayi prematur dengan usia gestasi antara 25 dan 32 minggu untuk mengeksplorasi peran dan persepsi mereka. Ini merupakan pengalaman pertama sebagai ayah 
untuk semua partisipan, namun ada 1 partisipan yang tidak. Wawancara dilakukan mulai 1 bulan setelah kelahiran bayi dan dilanjutkan di rumah sampai 3-4 bulan setelah bayi pulang dari rumah sakit. Larry adalah seorang ayah berusia 22 tahun yang memiliki bayi yang usia gestasi 25 minggu. Larry menggambarkan perasaannya terhadap putrinya, Leah. Dia menjelaskan : "Saya tidak suka jika tidak berada didekatnya. Jika itu terjadi pada saya, saya akan mengambil dan menahannya (dirumahnya)... karena saya tidak suka jika putri saya berada di NICU dengan orang-orang yang tidak peduli padanya...itu bukan bayi mereka, sehingga mereka tidak tahu bagaimana perasaan dekat dengannya seperti saya”.

Ilustrasi diatas menunjukkan pengaruh kekuatan dari masa lalu seseorang, khususnya seorang ayah yang memiliki kemampuan untuk percaya diri dalam mencari tahu tentang bayinya. Percaya diri adalah aset untuk fokus pada apa yang dibutuhkan ibu dan bayinya (Pohlman, 2009).

Penelitian menjelaskan tentang pengalaman ayah yang bayinya prematur, telah dilakukan oleh Lindberg, Axelsson dan Ohrling (2007). Penelitian ini menemukan tiga pengalaman yang berbeda yaitu (1) kelahiran prematur yang tiba-tiba dan perasaan tidak siap menjadi ayah; (2) peran mereka sebagai penanggung jawab atas kesejahteraan keluarga baru dan (3) kebutuhan untuk dipahami oleh staf NICU. Ini menunjukkan pentingnya menyoroti pengalaman ayah sebagaimana pengalaman seorang ibu yang bayinya prematur.

Garten, Nazary, Metze dan Buhrer (2013) melaporkan dalam penelitiannya pada 111 partisipan (ayah bayi) bahwa selama bayi dirawat di NICU, ayah bayi mempersepsikan bahwa peran mereka adalah memberikan kehangatan fisik pada bayi $(81,1 \%)$, memberikan dukungan emosional pada ibu bayi $(75,7 \%)$ dan mengatur kehidupan keluarga sehari-hari $(55,9 \%)$. Hampir semua ayah bayi $(97,2 \%)$ percaya bahwa kunjungan mereka ke NICU memberikan efek yang positif bagi perkembangan kesehatan bayinya dan bermanfaat bagi hubungan ayahbayi.

Akan tetapi, Garten et al. (2013) mengungkapkan ayah bayi melaporkan bahwa memiliki bayi berat lahir sangat rendah yang dirawat di NICU memberikan dampak negatif bagi pekerjaan, kesehatan dan hubungannya dengan orang lain. Hal senada juga dijelaskan oleh Pohlman (2009) bahwa menghabiskan waktu di NICU bukanlah prioritas utama bagi ayah bayi. Mereka fokus pada target di luar NICU seperti pekerjaan yang memberikan kepuasan, karena mereka bertanggungjawab pada keuangan keluarga.

\section{Peran Perawat}

Di rumah sakit, orang tua merasa cemas dan gelisah dengan suasana di NICU. Orangtua khawatir tentang peran mereka sebagai orangtua, takut harus menghadapi konsekuensi seperti penampilan bayi, kondisi mental bayi dan kematian (Heidari et al., 2013). Systematic review yang dilakukan oleh Obeidat, Bond dan Callister (2009) mengungkapkan bahwa orangtua mengalami depresi, kecemasan, stres dan kehilangan kontrol saat bayinya dirawat di NICU. Orangtua juga memiliki perasaan terombang-ambing terkait dengan penyediaan layanan kesehatan untuk bayi mereka.

Russel et al. (2014) dalam penelitian kualitatifnya pada 32 ibu dan 7 orang ayah tentang pandangan orangtua terhadap bayi prematur yang dirawat di NICU menyimpulkan bahwa penyediaan informasi, dukungan dan peningkatan keterlibatan orangtua dalam perawatan bayi dinilai oleh orangtua sangat penting bagi pengalaman perawatan mereka. Hal ini dapat membantu mengurangi kecemasan dan tekanan. Temuan dalam penelitian ini juga menunjukkan pentingnya perawatan yang berpusat pada keluarga (Family Centered Care/FCC).

Hal senada diungkapkan oleh Obeidat et al. (2009) bahwa intervensi harus fokus pada perawatan yang berpusat pada keluarga (FCC) dan perawatan yang mendukung perkembangan bayi untuk mengurangi perasaan stres orangtua, kecemasan dan kehilangan kontrol. 
Garten, Nazary, Metze dan Buhrer (2013) menjelaskan ayah bayi yang menjadi partisipan dalam penelitiannya melaporkan komplain mereka tentang kekurangan waktu dengan staf NICU selama periode perawatan. Mereka tidak mendapatkan intervensi khusus seperti kursus, seminar dan workshop tentang bayi berat lahir rendah, konseling psikologis dan pertemuan rutin dengan tim konseling psikologis keluarga.

Salah satu dari tema utama yang menentukan kepuasan orangtua terhadap perawatan neonatal dalam penelitian Russel et al. (2014) adalah staf yang kompeten dan efisien (termasuk komunikasi, pengalaman, kepercayaan diri, penjelasan dan pemberian informasi dari staf). Tingkat komunikasi saat pertemuan dengan staf NICU memiliki pengaruh yang menentukan bagi pengalaman orangtua dalam rangka pengelolaan situasi yang mereka alami. Kurangnya komunikasi memberikan kontribusi perasaan kesepian, ditinggalkan dan tanggung jawab yang tidak diinginkan yang menambah beban bagi orangtua bayi (Wigert, Blom, \& Bry, 2014).

Russel et al (2014) mengungkapkan bahwa strategi yang jelas dan efektif harus digunakan untuk membantu komunikasi antara staf dan orangtua seperti catatan bayi yang diletakkan di bed bayi sehingga orang tua dapat mengakses informasi tentang bayinya.

Secara umum, memberikan informasi akan memungkinkan orangtua untuk berpartisipasi dalam proses pengambilan keputusan mengenai bayi mereka. Memperlakukan orangtua sebagai anggota tim juga dapat membantu mengurangi kecemasan orangtua. Selain itu, mengurangi dampak dari periode pemisahan antara ibu dan bayi dan memberikan informasi terbaru tentang kondisi bayi merupakan hal yang sangat penting untuk mengurangi ketakutan pada orangtua (Heidari, Hasanpour \& Fooladi, 2013).

Sebuah studi kualitatif dilakukan oleh Wigert et al. (2014) pada 18 keluarga (27 orangtua : 11 Ayah dan $16 \mathrm{Ibu}$ ) dengan menggunakan desain fenomenologi : A hermeneutic lifeworld interview study. Studi ini menunjukkan bahwa pengalaman komunikasi orangtua dengan staf NICU merupakan hal penting dalam pengelolaan situasi yang mereka alami. Komunikasi yang penuh dapat membantu orangtua menghadapi kondisi perawatan bayinya. Sebaliknya, kurangnya komunikasi memberikan kontribusi perasaan kesepian, ditinggalkan dan tanggung jawab yang tidak diinginkan yang menambah beban bagi orangtua bayi. Manajemen rumah sakit harus memfasilitasi komunikasi yang baik antara orangtua dan staf melalui pelatihan, pengelolaan staf dan lingkungan fisik perawatan yang baik.

\section{REFERENCES}

[3] A. Pragholapati and F. Munawaroh, "Resiliensi pada lansia," J. Surya Muda, vol. 2, no. 1, pp. 1-8, 2020.

[4] A. Pragholapati, F. Munawaroh, Stik. Jenderal Achmad Yani, and Stik. Bhakti Kencana Bandung, "RESILIENSI PADA LANSIA," ejurnal.ars.ac.id, vol. 2, no. 1, p. 2020.

[5] A. Pragholapati, "RESILIENSI PADA KONDISI WABAH COVID-19," 2020.

[6] A. Pragholapati, F. Munawaroh, Stik. Jenderal Achmad Yani, and Stik. Bhakti Kencana Bandung, "RESILIENSI PADA LANSIA," ojs.stikesmuhkendal.ac.id, vol. 2, no. 1, p. 2020.

[7] A. Pragholapati, "Hubungan masalah kesehatan jiwa dengan strategi koping seseorang yang mengalami perceraian di kota bandung," 2016.

[8] A. Pragholapati and W. Ulfitri, "Gambaran Mekanisme Coping pada Mahasiswa Program Studi Sarjana Keperawatan Tingkat IV yang Sedang Menghadapi Tugas Akhir di Sekolah Tinggi Ilmu Kesehatan X Bandung," Humanit. (Jurnal Psikologi), vol. 3, no. 2, pp. 115-126, 2019. 
[9] A. Pragholapati, R. S. Oktapiani, and Efri Widianti, "Pengaruh Brain Gym Terhadap Tingkat Depresi Pada Lansia Di Balai Perlindungan Sosial Tresna Werdha Ciparay Bandung," Sk. keperawatan, vol. 5, no. 2, pp. 128 146, 2019.

[10] A. Pragholapati, U. Padjadaran, and F. Keperawatan, "PERAWAT YANG BEKERJA DI UNIT GAWAT DARURAT ( UGD ) RUMAH SAKIT AL ISLAM ( RSAI ) BANDUNG THE CORRELATION OF RESILIENCY WITH NURSE' S WORK STRESS IN EMERGENCY UNIT RUMAH SAKIT AL ISLAM ( RSAI ) BANDUNG,” 2010.

[11] A. Ariani et al., "INFORMATION COMMUNICATION TECHNOLOGY ( ICT ) IN MIDWIFERY EDUCATION ( A REVIEW OF THE LITERATURE )," vol. 3, no. 1, pp. 2014-2017, 2019.

[12] A. Pragholapati, “COVID-19 IMPACT ON STUDENTS,” pp. 1-6, 2020.

[13] A. Pragholapati, "Self-Efficacy Of Nurses During The Pandemic Covid19," no. May 2020, p. 2020.

[14] A. Pragholapati, "HUBUNGAN BULLYING DENGAN KEMAMPUAN SOSIAL PADA REMAJA DI SMK X KOTA BANDUNG,” vol. 9, no. 1, pp. $34-40,2020$

\section{REFERENCES}

[1] Ariani, A., Pragholapati, A., \& Pratama, A. S. (2019). INFORMATION COMMUNICATION TECHNOLOGY (ICT) IN MIDWIFERY EDUCATION (A REVIEW OF THE LITERATURE). In The 3rd International Seminar on Global Health (Vol. 3, No. 1, pp. 66-69).

[2] Andria Pragholapati, R. (2018). DEVELOPMENT OF THE INDONESIAN NATIONAL QUALIFICATIONS FRAMEWORK FOR NURSING CURRICULUM. In International Conference on Education and Regional Development 3rd (ICERD) (p. 44).

[3] Pragholapati, A. (2020). COVID-19 IMPACT ON STUDENTS.

[4] Pragholapati, A. (2020). Self-Efficacy Of Nurses During The Pandemic Covid-19.

[5] Pragholapati, A., \& Munawaroh, F. (2020). Resiliensi pada lansia. Jurnal Surya Muda| Jurnal STIKES Muhammadiyah Kendal, 2(1), 1-8.

[6] Pragholapati, A. (2020). MENTAL HEALTH IN PANDEMIC COVID-19. Available at SSRN, 3596311.

[7] Andria Pragholapati, M. L. (2017). HUBUNGAN MASALAH KESEHATAN JIWA DENGAN STRATEGI KOPING SESEORANG YANG MENGALAMI PERCERAIAN DI KOTA BANDUNG. In Seminar Nasional Dan Workshop Keperawatan "Penguatan Profesi Keperawatan Dalam Peningkatan Pelayanan Keperawatan" Continuum of Care Dari Ketergantungan Menuju Kemandirian Hidup Yang Berkualitas.

[8] Pragholapati, A. (2019). THE EFFECT OF BRAIN GYM TO THE LEVEL OF DEPRESSION IN GERIATRIC AT BALAI PERLINDUNGAN SOSIAL TRESNA WERDHA CIPARAY BANDUNG. Jurnal Skolastik Keperawatan, 5(2), 128-146.

[9] Pragholapati, A. (2020). New Normal "Indonesia" After Covid-19 Pandemic. 
[10] Andria Pragholapati, T. (2018). HUBUNGAN PENGGUNAAN SMARTPHONE DENGAN KUALITAS TIDUR PADA REMAJA DI SMK X BANDUNG. Konferensi Nasional Keperawatan Kesehatan Jiwa XV Di Hotel Four Point By Sheraton Makassar Sulawesi Selatan, 1-7.

[11] Andria Pragholapati, R. M. (2017). HUBUNGAN BULLYING DENGAN KEMAMPUAN SOSIAL PADA REMAJA DI SMK MVP KOTA BANDUNG TAHUN 2017. Konferensi Nasional Keperawatan Kesehatan Jiwa XIV Di Kalimantan Selatan Tahun.

[12] Pragholapati, A. (2020). Depression in Someone Who Has Divorce.

[13] Pragholapati, A. (2020). The Role of Nurses in Divorce.

[14] Pragholapati, A. (2020). Anxiety in Someone Who Has Divorce.

[15] Pragholapati, A. (2020). Marriage and Divorce.

[16] Pragholapati, A. (2020). Mental Health Issues Someone Who Has Divorce.

[17] Pragholapati, A. (2020). George A. Beauchamp.

[18] Pragholapati, A. (2020). DEVELOPMENT OF CURRICULUM OF HIGHER EDUCATION (3 COUNTRIES).

[19] Pragholapati, A. (2020). DEVELOPMENT OF HIGHER EDUCATION CURRICULUM IN MALAYSIA EDUCATION DEVELOPMENT OF HIGHER EDUCATION CURRICULUM IN MALAYSIA EDUCATION SYSTEMS.

[20] Pragholapati, A. (2020). DEVELOPMENT OF HIGHER EDUCATION CURRICULUM IN THAILAND EDUCATION SYSTEM.

[21] Pragholapati, A. (2020). Coping Strategies for Someone Divorced.

[22] Pragholapati, A. (2020). DEVELOPMENT OF HIGHER EDUCATION CURRICULUM IN SINGAPORE EDUCATION SYSTEM.

[23] Pragholapati, A. (2020). GOVERNANCE IN MENTAL HEALTH NURSING. PsyArXiv. June, 13.

[24] Pragholapati, A. (2020). Parent Anxiety Levels In Hospitalization Children In RSUD Majalaya Kab. Bandung. Health Media, 1(2), 40-44.

[25] Ariani, A., Destyana, A., \& Pragholapati, A. (2020). GAMBARAN DUKUNGAN SUAMI TENTANG PROGRAM PERENCANAAN PERSALINAN DAN PENCEGAHAN KOMPLIKASI. Jurnal Maternitas Aisyah (JAMAN AISYAH), 1(2), 87-91.

[26] Pratama, A. S., Pragholapati, A., \& Nurrohman, I. (2020). Mekanisme Koping pada Pasien Gagal Ginjal Kronik yang menjalani Hemodialisis di Unit Hemodialisa RSUD Bandung. Jurnal Smart Keperawatan, 7(1), 18-21.

[27] PRAGHOLAPATI, A., \& Sarinengsih, Y. (2019). TINGKAT KECEMASAN PADA PASIEN ANAK USIA SEKOLAH (6-12 TAHUN) DI RUANG IGD RSUD MAJALAYA KABUPATEN BANDUNG. Bali Medika Jurnal, 6(1), 1-7.

[28] Pragholapati, A. (2020). GAMBARAN SESEORANG YANG BERCERAI DI KOTA BANDUNG. Jurnal Skolastik Keperawatan, 6(1), 42-48.

[29] Pragholapati, A. RESILIENSI PADA KONDISI WABAH COVID-19.

[30] Pragholapati, A. (2020). RESILIENSI PERAWAT YANG BEKERJA DI UNIT GAWAT DARURAT (UGD) RUMAH SAKIT AL ISLAM (RSAI) BANDUNG. 
[31] Pragholapati, A. (2020). STRES KERJA PERAWAT YANG BEKERJA DI UNIT GAWAT DARURAT (UGD) RUMAH SAKIT AL ISLAM (RSAI) BANDUNG.

[32] Pragholapati, A. (2020). MOTIVASI KERJA PERAWAT DI RUANG RAWAT INAP RSUD MAJALAYA KABUPATEN BANDUNG.

[33] Rohayani, L., Inayah, I., Shoumi, A. S., \& Pragholapati, A. (2020). Pelayanan Prima Perawat Berdasarkan Persepsi Pasien di Ruang Rawat Inap Talaga Bodas (Penyakit Dalam Pria Kelas 3) Rumah Sakit Tingkat II 03.05. 01 Dustira Cimahi 2019. Journal Of Health Science (Jurnal Ilmu Kesehatan), 5(1), 42-46.

[34] Hadiansyah, T., \& Pragholapati, A. (2020). KECEMASAN KELUARGA DALAM MERAWAT KLIEN SKIZOFRENIA. Jurnal Keperawatan'Aisyiyah, 7(1), 25-29.

[35] Pragholapati, A. RESILIENSI PADA KONDISI WABAH COVID-19.

[36] Pragholapati, A., Yosef, I., \& Soemantri, I. (2020). The Correlation of Resilience With Nurses Work Stress In Emergency Unit Rumah Sakit Al Islam (RSAI) Bandung. Sorume Health Sciences Journal, 1(1), 9-18. 